\title{
Ferric perchlorate-promoted reaction of [60]fullerene with $\beta$-keto esters
}

\author{
LI FaBao ${ }^{1,2}$, ZHU SanE ${ }^{2}$, YOU Xun ${ }^{2} \&$ WANG GuanWu ${ }^{2 *}$ \\ ${ }^{1}$ Ministry of Education Key Laboratory for the Synthesis and Application of Organic Functional Molecules, School of Chemistry and Chemical \\ Engineering, Hubei University, Wuhan 430062, China; \\ ${ }^{2}$ Hefei National Laboratory for Physical Sciences at Microscale, Department of Chemistry, University of Science and Technology of China, Hefei \\ 230026, China
}

Received November 12, 2011; accepted January 9, 2012; published online April 23, 2012

\begin{abstract}
The ferric perchlorate-promoted reaction of [60]fullerene $\left(\mathrm{C}_{60}\right)$ with ethyl 2-methylacetoacetate generates fullerenyl hemiketal as a mixture of trans and cis isomers, while the reaction with ethyl acetoacetate gives a $\mathrm{C}_{60}$-fused dihydrofuran derivative. A possible reaction mechanism for the formation of these products is proposed.
\end{abstract}

[60]fullerene, ferric perchlorate, $\beta$-keto esters, fullerenyl hemiketal, $\mathbf{C}_{60}$-fused dihydrofuran derivative

Citation: $\quad$ Li F B, Zhu S E, You X, et al. Ferric perchlorate-promoted reaction of [60]fullerene with $\beta$-keto esters. Chin Sci Bull, 2012, 57: 2269-2272, doi: $10.1007 / \mathrm{s} 11434-012-5103-5$

Various types of reactions for the functionalization of fullerenes have been developed over the past 20 years [1-3]. However, metal salt-promoted reactions of fullerenes have been somewhat neglected. Recently, we have investigated [60]fullerene $\left(\mathrm{C}_{60}\right)$ reactions mediated by metal salts such as $\mathrm{Mn}(\mathrm{OAc})_{3}$ [4-16], $\mathrm{Cu}(\mathrm{OAc})_{2}$ [7], $\mathrm{Pb}(\mathrm{OAc})_{4}$ [12], $\mathrm{Pd}(\mathrm{OAc})_{2}$ $[17,18]$, and $\mathrm{Fe}\left(\mathrm{ClO}_{4}\right)_{3}[19-21]$ to synthesize certain desired fullerene derivatives. $\mathrm{Fe}\left(\mathrm{ClO}_{4}\right)_{3}$ has been employed to promote the reaction of $\mathrm{C}_{60}$ with nitriles [19], aldehydes/ketones [20], and substituted malonate esters [21] to prepare $\mathrm{C}_{60^{-}}$ fused oxazoles, 1,3-dioxolanes, and lactones. In continuation of our interest in the $\mathrm{Fe}\left(\mathrm{ClO}_{4}\right)_{3}$-mediated reactions of $\mathrm{C}_{60}$ [19-21], we report the $\mathrm{Fe}\left(\mathrm{ClO}_{4}\right)_{3}$-promoted reaction of $\mathrm{C}_{60}$ with representative $\beta$-keto esters such as ethyl 2-methylacetoacetate and ethyl acetoacetate to give fullerenyl hemiketal and $\mathrm{C}_{60}$-fused dihydrofuran derivatives.

\section{Experimental}

\subsection{Materials}

$\mathrm{C}_{60}(>99.9 \%)$ was purchased from Henan Puyang Co., Ltd.

*Corresponding author (email: gwang@ustc.edu.cn)
Ferric(III) perchlorate was purchased from Alfa Aesar. Ethyl 2-methylacetoacetate, ethyl acetoacetate, acetic anhydride, and $o$-dichlorobenzene were all AR grade reagents. The reaction products were purified by flash chromatography over silica gel (200-300 mesh).

\subsection{Instrumentation}

The UV-vis spectra were measured in $\mathrm{CHCl}_{3}$ using a Shimadzu UV-2501 PC spectrometer. IR spectra were taken on a Shimadzu FTIR-8600 spectrometer with $\mathrm{KBr}$ pellets. ${ }^{1} \mathrm{H}$ NMR (300 MHz) and ${ }^{13} \mathrm{C}$ NMR (75 MHz) spectra were recorded on a Bruker AVANVE 300 spectrometer. Mass spectra were recorded on a BIFLEXIII MALDI-TOF mass spectrometer with 4-hydroxy- $\alpha$-cyanocinnamic acid as the matrix.

\subsection{Preparation of fullerenyl hemiketal 1}

A mixture of $\mathrm{C}_{60}(36.0 \mathrm{mg}, 0.05 \mathrm{mmol})$, ethyl 2-methylacetoacetate $(15 \mu \mathrm{L}, 0.1 \mathrm{mmol})$, and acetic anhydride $(95 \mu \mathrm{L}$, $1.00 \mathrm{mmol}$ ) was dissolved in $o$-dichlorobenzene $(6 \mathrm{~mL})$, and then the resulting solution was deoxygenated by means of a 
nitrogen stream for $10 \mathrm{~min}$. After $\mathrm{Fe}\left(\mathrm{ClO}_{4}\right)_{3} \cdot x \mathrm{H}_{2} \mathrm{O}(46.0 \mathrm{mg}$, $0.10 \mathrm{mmol}$, dissolved in $1 \mathrm{~mL}$ of acetonitrile) was added, the reaction mixture was heated under a nitrogen atmosphere with vigorous stirring in an oil bath preset at $80^{\circ} \mathrm{C}$ for $20 \mathrm{~min}$. The reaction solution was passed through a silica gel (100-200 mesh) plug to remove any insoluble material. After the solvent was vacuum evaporated, the residue was separated on a silica gel (100-200 mesh) column with carbon disulfide as the eluent to give unreacted $\mathrm{C}_{60}(24.2 \mathrm{mg}$, $67 \%$ ), then with carbon disulfide/toluene as the eluent for trans-1 (6.5 mg, 15\%) and then cis-1 (2.6 mg, 6\%). trans-1: ${ }^{1} \mathrm{H}$ NMR $\left(300 \mathrm{MHz}, \mathrm{CS}_{2} / \mathrm{CDCl}_{3}\right) \delta 5.70(\mathrm{~s}, 1 \mathrm{H}), 4.34(\mathrm{dq}$, $J=10.8,7.1 \mathrm{~Hz}, 1 \mathrm{H}), 4.25(\mathrm{dq}, J=10.8,7.1 \mathrm{~Hz}, 1 \mathrm{H}), 2.33$ (s, $3 \mathrm{H}), 2.11(\mathrm{~s}, 3 \mathrm{H}), 1.24(\mathrm{t}, J=7.1 \mathrm{~Hz}, 3 \mathrm{H}) ;{ }^{13} \mathrm{C}$ NMR $(75$ $\mathrm{MHz}, \mathrm{CS}_{2} / \mathrm{CDCl}_{3}$ with $\mathrm{Cr}(\mathrm{acac})_{3}$ as the relaxation reagent, all $1 \mathrm{C}$ unless indicated) $\delta 172.97,151.80,151.00,150.97$, $148.22,147.00,146.60,145.68,145.51$ (2C), 145.44, 145.32 (2C), 145.15, 145.11, 145.03, 144.95, 144.82, $144.79,144.76,144.70,144.43,144.30$ (2C), 144.23 (2C), $144.20,144.17$ (2C), 143.83, 143.68, 143.50, 143.42, $141.99,141.90,141.84,141.78,141.68$ (2C), 141.45 (2C), 141.33 (3C), 141.08, 140.99, 140.83 (2C), 140.59, 140.50, $140.23,138.90,138.67,138.13$ (2C), 137.75, 137.21, $137.16,136.37,107.65,97.55\left(\mathrm{sp}^{3}-\mathrm{C}\right.$ of $\left.\mathrm{C}_{60}\right), 72.83\left(\mathrm{sp}^{3}-\mathrm{C}\right.$ of $\left.\mathrm{C}_{60}\right), 63.74,61.63,22.99,22.76,13.33$; FT-IR $v / \mathrm{cm}^{-1}$ (KBr) 2924, 1708, 1432, 1378, 1279, 1111, 1042, 1011, 938, 575, 526; UV-vis $\left(\mathrm{CHCl}_{3}\right) \lambda_{\max } / \mathrm{nm}(\log \varepsilon) 256$ (4.93), 314 (4.45), 427 (3.24), 691 (2.24); MS (-MALDI TOF) $\mathrm{m} / \mathrm{z} 880$ $\left(\mathrm{M}^{-}\right)$. cis-1: ${ }^{1} \mathrm{H} \mathrm{NMR}\left(300 \mathrm{MHz}, \mathrm{CS}_{2} / \mathrm{CDCl}_{3}\right) \delta 4.50(\mathrm{dq}, J=$ $10.9,7.1 \mathrm{~Hz}, 1 \mathrm{H}), 4.37(\mathrm{dq}, J=10.9,7.1 \mathrm{~Hz}, 1 \mathrm{H}), 3.12(\mathrm{~s}$, $1 \mathrm{H}), 2.15(\mathrm{~s}, 3 \mathrm{H}), 2.08(\mathrm{~s}, 3 \mathrm{H}), 1.48(\mathrm{t}, J=7.1 \mathrm{~Hz}, 3 \mathrm{H}) ;{ }^{13} \mathrm{C}$ NMR (75 MHz, $\mathrm{CS}_{2} / \mathrm{DMSO}-d_{6}$ with $\mathrm{Cr}(\mathrm{acac})_{3}$ as the relaxation reagent, all 1C unless indicated) $\delta 169.39,152.56$, $152.16,151.98,148.10,146.10,145.51,144.59,144.40$ (2C), 144.35, 144.32, 144.29 (2C), 144.08 (3C), 144.03, $143.93,143.79,143.72,143.52,143.47,143.39,143.21$ (3C), 143.19, 143.10, 143.04, 142.86 (2C), 142.56, 141.08, $141.02,140.79,140.71(3 \mathrm{C}), 140.45,140.40$ (2C), 140.25 (2C), 140.13, 140.08, 140.01, 139.76, 139.69, 139.66, $139.53,137.71,137.57$ (2C), 137.44, 137.39, 136.82, $136.26,135.98,105.67,95.78\left(\mathrm{sp}^{3}-\mathrm{C}\right.$ of $\left.\mathrm{C}_{60}\right), 73.52\left(\mathrm{sp}^{3}-\mathrm{C}\right.$ of $\left.\mathrm{C}_{60}\right), 65.88,59.85,21.10,17.46,13.10$; FT-IR $v / \mathrm{cm}^{-1}$ (KBr) 2924, 1728, 1448, 1381, 1256, 1158, 1111, 1011, 932, 575, 527; UV-vis $\left(\mathrm{CHCl}_{3}\right) \lambda_{\max } / \mathrm{nm}(\log \varepsilon) 255$ (5.00), 314 (4.52), 427 (3.30), 693 (2.49); MS (-MALDI TOF) $\mathrm{m} / \mathrm{z} 880$ $\left(\mathrm{M}^{-}\right)$.

\subsection{Preparation of fullerenyl dihydrofuran 2}

Using the same procedure as for the preparation of fullerene hemiketal 1, the reaction of $\mathrm{C}_{60}(36.0 \mathrm{mg}, 0.05 \mathrm{mmol})$ with ethyl acetoacetate $(13 \mu \mathrm{L}, 0.1 \mathrm{mmol}), \mathrm{Fe}\left(\mathrm{ClO}_{4}\right)_{3} \cdot x \mathrm{H}_{2} \mathrm{O}(46.0$ $\mathrm{mg}, 0.10 \mathrm{mmol})$, and acetic anhydride $(95 \mu \mathrm{L}, 1.00 \mathrm{mmol})$ at $80^{\circ} \mathrm{C}$ for 30 min gave the unreacted $\mathrm{C}_{60}(26.8 \mathrm{mg}, 74 \%)$ and $\mathrm{C}_{60}$-fused dihydrofuran derivative 2 [7,22-24] (8.4 mg, $20 \%)$.

\section{Results and discussion}

Our success in the $\mathrm{Fe}\left(\mathrm{ClO}_{4}\right)_{3}$-mediated reaction of $\mathrm{C}_{60}$ with substituted malonate esters [21] prompted us to extend the substrates to $\beta$-keto esters such as ethyl 2-methylacetoacetate and ethyl acetoacetate in the presence of acetic anhydride $\left(\mathrm{Ac}_{2} \mathrm{O}\right)$.

The reaction of $\mathrm{C}_{60}$ with ethyl 2-methylacetoacetate was found to exclusively give hemiketal $\mathbf{1}$ as a mixture of the trans and cis isomers rather than $\mathrm{C}_{60}$-fused lactone (Scheme 1). The trans and cis isomers of hemiketal $\mathbf{1}$ differed significantly in polarity and could be easily separated by column chromatography over silica gel giving $15 \%$ and $6 \%$ yields ( $45 \%$ and $18 \%$ based on consumed $\mathrm{C}_{60}$ ), respectively.

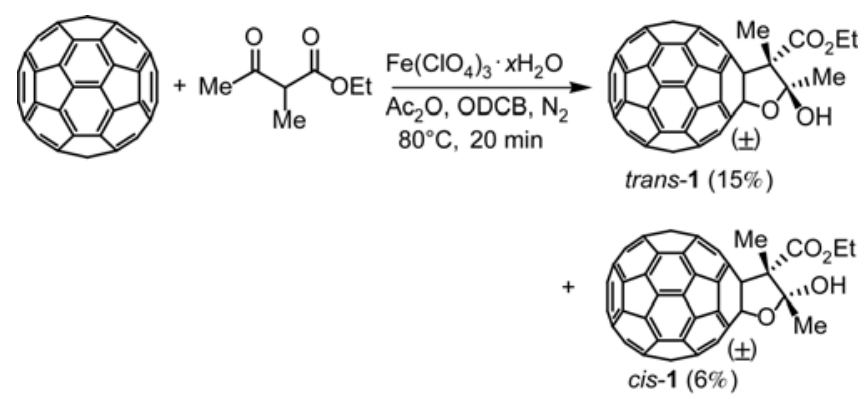

Scheme $1 \mathrm{Fe}\left(\mathrm{ClO}_{4}\right)_{3}$-mediated reaction of $\mathrm{C}_{60}$ with 2-methylacetoacetate in the presence of $\mathrm{Ac}_{2} \mathrm{O}$.

The identities of both trans-1 and cis-1 isomers were confirmed by MS, ${ }^{1} \mathrm{H}$ NMR, ${ }^{13} \mathrm{C}$ NMR, FT-IR, and UV-vis spectra. In the ${ }^{1} \mathrm{H}$ NMR spectra of both trans-1 and cis-1 isomers, the two methylene protons in the ethoxy group were nonequivalent and split as two double quartets due to the adjacent chiral center, which was analogous to those of $\mathrm{C}_{60}$-fused lactones [21]. The assignments of trans-1 and cis-1 isomers were confirmed by nuclear Overhauser enhancement spectroscopy (NOESY) spectra (Figure 1), where a cross peak between the methyl protons $(\delta 1.48)$ of the ethoxy group and hydroxyl proton $(\delta 3.12)$ could only be found in the cis-1 isomer. ${ }^{13} \mathrm{C}$ NMR spectra of trans-1 and cis-1 isomers showed similar spectral patterns. The two sp ${ }^{3}$-carbons of the $\mathrm{C}_{60}$ cage were located at $\delta 72.83-73.52$ and $\delta 95.78-$ 97.55 , and the observation of at least 46 lines in the $\delta 135$ 153 range for the $58 \mathrm{sp}^{2}$-carbons of the $\mathrm{C}_{60}$ skeleton including some overlapped ones was consistent with the $C_{1}$ symmetry of their molecular structures. The chemical shift for the hemiketal carbon in the trans isomer $(\delta 107.65)$ was shifted downfield about 2 relative to that in the cis isomer $(\delta 105.67)$. A similar phenomenon has been previously observed $[25,26]$. 
(a)
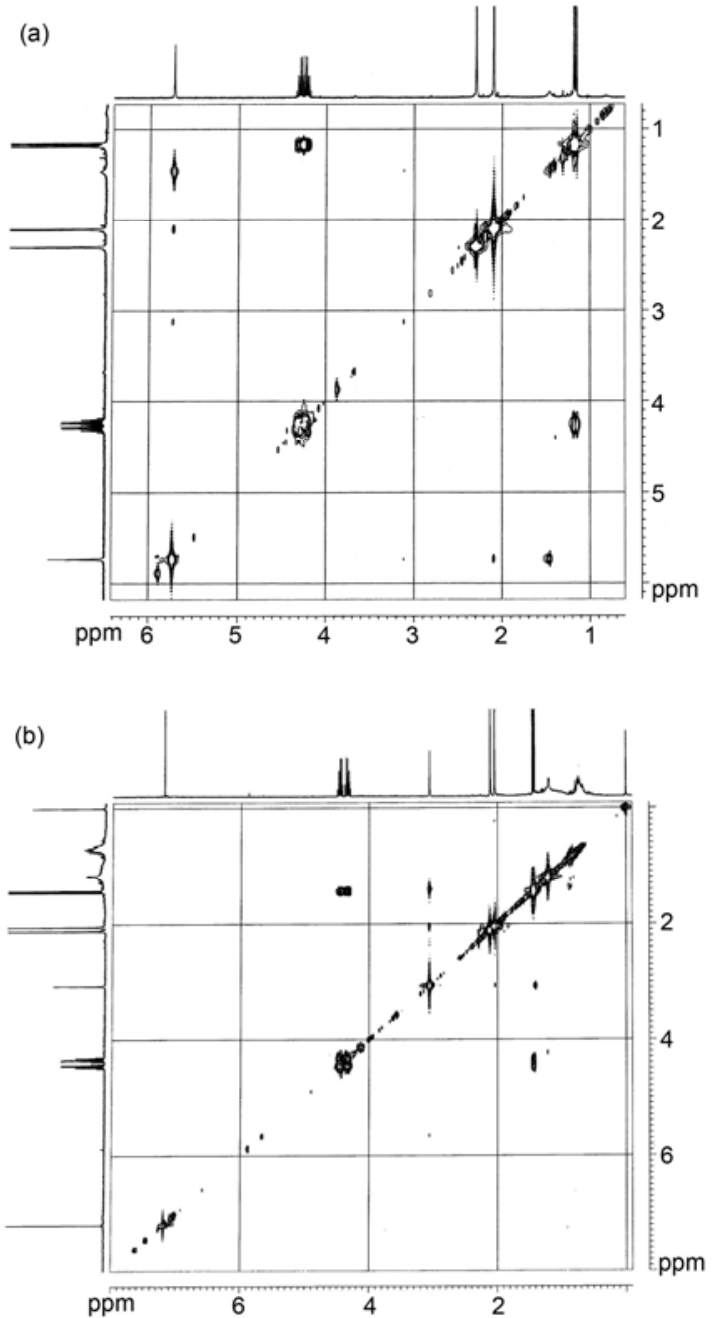

Figure 1 (a) NOESY spectra of the trans isomer of hemiketal 1. (b) NOESY spectra of the cis isomer of hemiketal 1.

Theoretical calculations were further exploited to support our assignments of trans-1 and cis-1 isomers. The relative energy of the trans-1 and cis-1 isomers calculated at the B3LYP/6-31G* level showed that the trans-1 isomer was $0.65 \mathrm{kcal} / \mathrm{mol}$ more stable than the cis-1 isomer (Figure 2), consistent with the higher product yield of the trans-1 isomer.

Fullerenyl hemiketals and kemiacetals are scarce in the literature [27]. Here we provide a new protocol to access fullerenyl hemiketals via a simple one-pot procedure. In addition, the hydroxy group of hemiketals $\mathbf{1}$ has the potential for further functionalization such as esterification and etherification to obtain various fullerene derivatives.

In comparison, the reaction of $\mathrm{C}_{60}$ with ethyl acetoacetate afforded neither a $\mathrm{C}_{60}$-fused lactone nor a hemiketal derivative, instead yielding mainly the known $\mathrm{C}_{60}$-fused dihydrofuran derivative 2 [7,22-24] in $20 \%$ yield (77\% based on consumed $\mathrm{C}_{60}$ ) (Scheme 2).

Although the exact pathway is not known for the formation of hemiketal $\mathbf{1}$ and $\mathrm{C}_{60}$-fused dihydrofuran derivative 2 , a possible reaction mechanism is shown in Scheme 3.

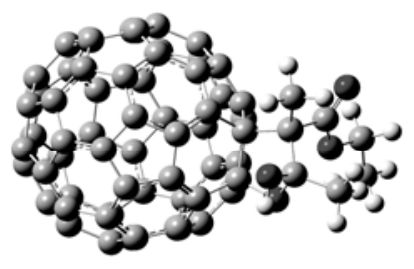

trans-1

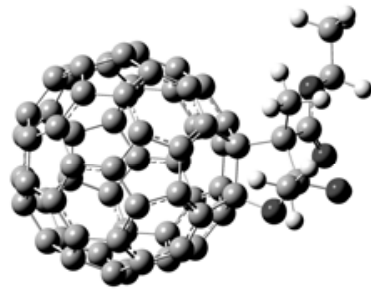

cis-1
Figure 2 Optimized geometries of the trans and cis isomers of hemiketal 1.

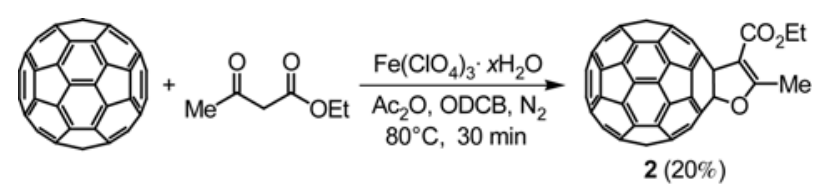

Scheme $2 \mathrm{Fe}\left(\mathrm{ClO}_{4}\right)_{3}$-mediated reaction of $\mathrm{C}_{60}$ with ethyl acetoacetate in the presence of $\mathrm{Ac}_{2} \mathrm{O}$.
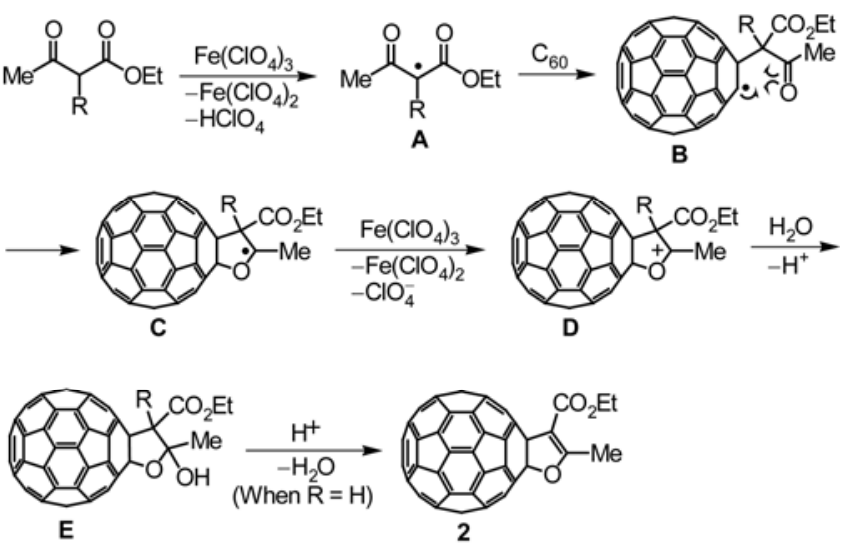

$(E=1$ when $\mathrm{R}=\mathrm{Me})$

Scheme 3 Proposed reaction mechanism for the formation of products 1 and 2 .

Ethyl 2-methylacetoacetate, or ethyl acetoacetate reacts with $\mathrm{Fe}\left(\mathrm{ClO}_{4}\right)_{3}$ to generate radical $\mathrm{A}$ along with the formation of $\mathrm{Fe}\left(\mathrm{ClO}_{4}\right)_{2}$ and $\mathrm{HClO}_{4}$ [28,29]. Addition of radical $\mathbf{A}$ to $\mathrm{C}_{60}$ produces fullerenyl radical $\mathbf{B}$, which undergoes intramolecular cyclization to give radical $\mathbf{C}$. Oxidation of radical $\mathbf{C}$ by another molecule of $\mathrm{Fe}\left(\mathrm{ClO}_{4}\right)_{3}$ results in cation $\mathbf{D}$ accompanied by counteranion $\mathrm{ClO}_{4}^{-}$and $\mathrm{Fe}\left(\mathrm{ClO}_{4}\right)_{2}$. However, an alternative pathway leading to $\mathbf{D}$ via the oxidation of $\mathbf{B}$ followed by cyclization cannot be excluded. The addition of $\mathrm{H}_{2} \mathrm{O}$, originated from the water of hydration in $\mathrm{Fe}\left(\mathrm{ClO}_{4}\right)_{3}$. $x \mathrm{H}_{2} \mathrm{O}$ or concomitant water in the system, to cation $\mathbf{D}$ with the loss of $\mathrm{H}^{+}$results in $\mathbf{E}$, which is actually hemiketal $\mathbf{1}$ when $\mathrm{R}=\mathrm{Me}$. In the case of $\mathrm{R}=\mathrm{H}$, elimination of $\mathrm{H}_{2} \mathrm{O}$ from intermediate $\mathbf{E}$ catalyzed by $\mathrm{H}^{+}$gives the $\mathrm{C}_{60}$-fused dihydrofuran derivative 2 . Other alternative reaction mechanisms may exist. For example, when ethyl acetoacetate is employed as the substrate, a reaction pathway via enolate salt 
formation followed by homolytical addition to $\mathrm{C}_{60}$ and subsequent cyclization may also operate [7]. In addition, direct loss of $\mathrm{H}^{+}$from intermediate $\mathbf{D}$ can also produce a $\mathrm{C}_{60}$-fused dihydrofuran derivative 2 when $\mathrm{R}=\mathrm{H}$.

\section{Conclusion}

The $\mathrm{Fe}\left(\mathrm{ClO}_{4}\right)_{3}$-mediated reaction of $\mathrm{C}_{60}$ with $\beta$-keto esters such as ethyl 2-methylacetoacetate and ethyl acetoacetate under similar reaction conditions resulted in fullerenyl hemiketal 1 and $\mathrm{C}_{60}$-fused dihydrofuran derivative $\mathbf{2}$, respectively. A plausible reaction mechanism involving the same type of intermediates in the first several steps is proposed to explain the formation of both products $\mathbf{1}$ and 2 .

This work was supported by the National Natural Science Foundation of China $(20972145,21132007,21102041)$.

1 Taylor R, Walton D R M. The chemistry of fullerenes. Nature, 1993, 363: 685-693

2 Hirsch A. Principles of fullerene reactivity. Top Curr Chem, 1999, 199: 1-65

3 Thilgen C, Diederich F. Structural aspects of fullerene chemistryA journey through fullerene chirality. Chem Rev, 2006, 106: 5049_ 5135

4 Wang G W, Li F B. Radical reactions of [60] fullerene mediated by manganese(III) acetate dihydrate. J Nanosci Nanotech, 2007, 7: $1162-1175$

5 Zhang T H, Lu P, Wang F, et al. Reaction of [60]fullerene with free radicals generated from active methylene compounds by manganese(III) acetate dihydrate. Org Biomol Chem, 2003, 1: 4403-4407

6 Wang G W, Zhang T H, Cheng X, et al. Selective addition to [60] fullerene of two different radicals generated from $\mathrm{Mn}$ (III)-based radical reaction. Org Biomol Chem, 2004, 2: 1160-1163

7 Wang G W, Li F B. Cu(II) acetate- and Mn(III) acetate-mediated radical reactions of [60]fullerene with ketonic compounds. Org Biomol Chem, 2005, 3: 794-797

8 Chen Z X, Wang G W. One-pot sequential synthesis of acetoxylated [60]fullerene derivatives. J Org Chem, 2005, 70: 2380-2383

9 Cheng X, Wang G W, Murata Y, et al. Solvent-free synthesis of dihydrofuran-fused [60]fullerene derivatives by high-speed vibration milling. Chin Chem Lett, 2005, 16: 1327-1329

10 Wang G W, Yang H T, Miao C B, et al. Radical reactions of [60] fullerene with $\beta$-enamino carbonyl compounds mediated by manganese(III) acetate. Org Biomol Chem, 2006, 4: 2595-2599

11 Wang G W, Li F B, Zhang T H. [60]Fullerene-fused lactones: Manganese(III) acetate-mediated synthesis and novel reductive ring opening. Org Lett, 2006, 8: 1355-1358

12 Li F B, Liu T X, Huang Y S, et al. Synthesis of fullerene-fused lactones and fullerenyl esters: Radical reaction of [60]fullerene with carboxylic acids promoted by manganese(III) acetate and lead(IV) acetate. J Org Chem, 2009, 74: 7743-7749

13 Li F B, Zhu S E, Wang G W. Manganese(III) acetate-mediated radical reaction of [60]fullerene with bromoacetic acid, 3-chloropropionic acid or 1-naphthylacetic acid. Chin Sci Bull, 2010, 55: 2909-2914

14 Wang G W, Wang C Z, Zhu S E, et al. Manganese(III) acetate-mediated radical reaction of [60]fullerene with phosphonate esters affording unprecedented separable singly-bonded [60]fullerene dimmers. Chem Commun, 2011, 47: 6111-6113

15 Wang G W, Wang C Z, Zou J P. Radical reaction of [60]fullerene with phosphorus compounds mediated by manganese(III) acetate. J Org Chem, 2011, 76: 6088-6094

16 Liu T X, Li F B, Wang G W. Synthesis of [60]fullerene-fused tetrahydronaphthalene and indane derivatives via a pathway switched by aluminum chloride. Org Lett, 2011, 13: 6130-6133

17 Zhu B, Wang G W. Synthesis of [60]fulleroindolines: Palladiumcatalyzed heteroannulations of [60]fullerene with $o$-iodoanilines. J Org Chem, 2009, 74: 4426-4428

18 Zhu B, Wang G W. Palladium-catalyzed heteroannulation of [60] fullerene with anilides via C-H bond activation. Org Lett, 2009, 11: 4334-4337

19 Li F B, Liu T X, Wang G W. Synthesis of fullerooxazoles: Novel reactions of [60]fullerene with nitriles promoted by ferric perchlorate. J Org Chem, 2008, 73: 6417-6420

20 Li F B, Liu T X, You X, et al. A facile access to [60]fullerene-fused 1,3-dioxolanes: Reaction of [60]fullerene with aldehydes/ketones promoted by ferric perchlorate. Org Lett, 2010, 12: 3258-3261

21 Li F B, You X, Wang G W. Synthesis of disubstituted [60]fullerenefused lactones: Ferric perchlorate-promoted reaction of [60]fullerene with malonate esters. Org Lett, 2010, 12: 4896-4899

22 Ohno M, Yashiro A, Eguchi S. Base-catalysed oxidative [3+2] cycloaddition reaction of [60]fullerene with $\beta$-dicarbonyl compounds. Chem Commun, 1996, 291-292

23 Wang G W, Zhang T H, Li Y J, et al. Novel solvent-free reaction of $\mathrm{C}_{60}$ with active methylene compounds in the presence of $\mathrm{Na}_{2} \mathrm{CO}_{3}$ under high-speed vibration milling. Tetrahedron Lett, 2003, 44: 44074409

24 Zhang T H, Wang G W, Lu P, et al. Solvent-free reactions of $\mathrm{C}_{60}$ with active methylene compounds, either with or without carbon tetrabromide, in the presence of bases under high-speed vibration milling conditions. Org Biomol Chem, 2004, 2: 1698-1702

25 Wang G W, Li F B, Chen Z X, et al. Synthesis of [60]fullerene acetals and ketals: Reaction of [60]fullerene with aldehydes/ketones and alkoxides. J Org Chem, 2007, 72: 4779-4783

26 Wang G W, Lu Y M, Chen Z X, et al. An alternative type of fullerene products from the reaction of [60]fullerene with alkoxides and subsequent derivatization. J Org Chem, 2009, 74: 4841-4848

27 Wang G W, Li F B, Xu Y. Novel functionalizations of [60]fullerenefused lactones. J Org Chem, 2007, 72: 4774-4778

28 Citterio A, Sebastiano R, Marion A, et al. Synthesis of substituted tetrahydronaphthalenes by $\mathrm{Mn}(\mathrm{III}), \mathrm{Ce}(\mathrm{IV})$, and $\mathrm{Fe}(\mathrm{III})$ oxidation of substituted diethyl $\alpha$-benzylmalonates in the presence of olefins. J Org Chem, 1991, 56: 5328-5335

29 Citterio A, Sebastiano R, Carvayal M C. Oxidation of diethyl (pyridylmethy1)malonates with $\mathrm{Mn}(\mathrm{III})$ acetate, $\mathrm{Ce}(\mathrm{IV})$ ammonium nitrate, and iron(III) perchlorate in the presence of alkenes and alkynes. J Org Chem, 1991, 56: 5335-5341

Open Access This article is distributed under the terms of the Creative Commons Attribution License which permits any use, distribution, and reproduction in any medium, provided the original author(s) and source are credited. 